\title{
Article \\ Research on the Industrial Upgrade of Vegetable Growers in Shaanxi: A Cross-Regional Comparative Analysis of Experience Reference
}

\author{
Hongyu Wang ${ }^{1,2}$, Apurbo Sarkar ${ }^{1,2}$, Airin Rahman ${ }^{3,4}$, Md. Shakhawat Hossain ${ }^{5}$, Waqar Hussain Memon ${ }^{6}$ \\ and Lu Qian $1,2, *$ (D)
}

check for

updates

Citation: Wang, H.; Sarkar, A.; Rahman, A.; Hossain, M.S.; Memon, W.H.; Qian, L. Research on the Industrial Upgrade of Vegetable Growers in Shaanxi: A

Cross-Regional Comparative Analysis of Experience Reference. Agronomy 2022, 12, 38. https:// doi.org/10.3390/agronomy12010038

Academic Editor: Magdalena Sobocińska

Received: 30 September 2021 Accepted: 21 December 2021 Published: 24 December 2021

Publisher's Note: MDPI stays neutral with regard to jurisdictional claims in published maps and institutional affiliations.

Copyright: (C) 2021 by the authors. Licensee MDPI, Basel, Switzerland. This article is an open access article distributed under the terms and conditions of the Creative Commons Attribution (CC BY) license (https:// creativecommons.org/licenses/by/ $4.0 /$ )
1 College of Economics and Management, Northwest A\&F University, Xianyang 712100, China; wanghongyu@nwafu.edu.cn (H.W.); apurbo@nwafu.edu.cn (A.S.)

2 The Sixth Industry Research Institute, Northwest A\&F University, Xianyang 712100, China

3 School of Finance and Economics, Jiangsu University, Zhenjiang 212013, China; airinsauh2015@gmail.com

4 Department of Agribusiness and Marketing, Sher-E-Bangla Agricultural University, Dhaka 1207, Bangladesh

College of Agronomy, Northwest A\&F University, Xianyang 712100, China; shakhawat@nwafu.edu.cn

6 School of Mechanical Engineering, Nanjing University of Science and Technology, Xiaoling Wei, Nanjing 210014, China; mechengr2020@hotmail.com

* Correspondence: luqian@nwafu.edu.cn

\begin{abstract}
The prime goals of this article are to classify farmers' production structures in different regions through comparative analysis and propose a structural framework that can quantify the transformation and upgrade of the vegetable industry in Shaanxi. The study utilized New Structural Economics (NSE) theory to construct the theoretical model, and the empirical data set has been crafted from 1992 vegetable growers in the Shaanxi, Hebei, and Shandong provinces. We qualitatively evaluated the potentiality of the Shaanxi vegetable industry, facilitating an industrial upgrade by drawing on the development experience of other regions. More specifically, we utilized the tomato growers to construct a five-step analysis method to transform and upgrade the vegetable industries. This article found that the chosen three provinces have structural differences and similarities in their production sides, and, compared with Hebei and Shandong, the vegetable industry in Shaanxi is still in the catching-up stage. Hebei has similar planting characteristics to Shaanxi, but the production characteristics of growers in Shaanxi are quite different from those in Shandong. Therefore, tomato growers in Hebei are the desired learning object for growers in Shaanxi. By learning planting experience from Hebei growers, tomato growers in the Shaanxi Province can improve their yield and product quality. We found that Shaanxi farmers have 15.57 percent improvement potential in improving crop management and rational allocation of production materials. Proper informationsharing platforms should be implemented to grasp consumption trends on the demand side and guide industrial upgrading.
\end{abstract}

Keywords: new structural economics; vegetable industry; industrialization; rural development; rural revitalization

\section{Introduction}

Since China's economic reform, local revitalization has become a significant endeavor for national, municipal, and regional authorities [1]. At the same time, the framework for local growth has been radically modified using structured economic activities, which have made it much more difficult [2,3]. Industrialization of farming implies transformations from conventional farming to modernized farming [4,5], which involves several tactics to facilitate a proper combination of endogenous knowledge with technology, innovativeness, and modern science and technologies [6,7]. Every economically developed country in the world has undergone a rapid transformation of their agricultural sector to support the everincreasing demands for goods and services. If we explore the favorable and unfavorable 
growth perspectives, it is apparent that all these countries have a sound structural balance between their rural and urban areas, and there are minimal differences among the relative regions [8-10]. For example, Japan has a ratio of regional differences of approximately 1:0.9 in terms of agricultural sectors. The prime reason is that they implement a campaign that quantifies a learning environment based on regional cooperation.

Second, the farmers of those countries facilitate the rapid transition of technological advancements and innovativeness [11]. The Chinese agricultural sector has made tremendous progress in the past 40 years, especially after the reform initiatives fostering core conceptual advancements and innovative mechanisms [12]. Industrial prosperity is the core and foundation of rural revitalization. China's regional difference (rural-urban) ratio is currently at 2.7:1, which specifies a prominent characteristic of the dual economic arrangement of semi-structured industrialization $[13,14]$. The situation might act as the prime burden of achieving China's goals of reaching the status of a developed county $[15,16]$. Moreover, these uneven developments also possess major opportunities for facilitating interregional development. However, interregional learning facilities should be developed and exercised firmly [17].

In academic circles, the upgrade of agricultural industries has been discussed from various perspectives, such as value integrating and upgrading agricultural industries [18-20], comparing agricultural industries in different economies [21,22], and the Structure-ConductPerformance (SCP) research paradigm [23-25]. The theory of the structure conduct performance is the theoretical basis of industrial integration and upgrading. By participating in higher value-added industrial chain links, such as post-production processing, marketing, brand building, etc., farmers can integrate agriculture with the secondary and tertiary industries and increase their incomes [26-28]. The less developed areas often want to find out the reasons for their backward position through contrastive analysis by referring to the relevant economic development experience of the developed economies [29,30]. One of the main development trends in the Chinese agricultural sector is the rising production and transition cost [31,32].

Many scholars have further analyzed the reasons for the cost expansion of the live pig industry [33-35], grain industry [36,37], and apple industry [38] hoping to find the development experience that can be used for reference to other regions. Furthermore, some scholars have also explored the way to enhance the competitiveness of the agricultural industry from the system, as well as policy perspectives, by comparing the agricultural support policies such as environmental management between China, Japan, and the African Unions [39]; agricultural support policies between China, Japan, and South Korea [40]; and agricultural support level between China, America, Europe, Japan, and South Korea [41]. However, these comparative studies are all about the impact of a single factor on industrial upgrading [42-44], while the SCP research paradigm comprehensively proposes to analyze the competitive industrial advantage by using the diamond model composed of six factors $[45,46]$. In addition, some scholars have noted that the impact of other single factors on industrial development is mainly concentrated in such fields as the export quality of agricultural products $[47,48]$, Internet and Information Technology $[49,50]$, the interaction of informal finance [51,52], or the impacts of technological progress [53,54], etc. Interestingly, the current research on upgrading the vegetable industry mainly focuses on the industrial organization model $[55,56]$, integrative development of the vegetable industry, and other industries $[57,58]$.

Although previous research is of significance, the existing models for upgrading the agricultural industry have some defects. A multi-factor analysis is necessary for any structural upgrades, while an analysis with only one factor ignores the relationship between factors. The SCP paradigm of industrial structure upgrading, though comprehensive, ignores the hierarchy and internal relationships among the various factors. Factors of production indicate that industrial selection shall be based on the fact that factor endowment determines comparative advantages, and the comparative advantages are the basis of competitive advantages [59-61]. Nevertheless, industrial clusters, competitive markets, 
and demand conditions are the results of development rather than conditions, and only by choosing industrial markets based on comparative advantages can the industry be fully competitive. When an industry conforms to the comparative advantage determined by the country's factor endowment structure, the product is launched in the export market, so the demand side provides good market conditions for enterprises. From the perspective of contrastive analysis, the vast majority of current comparative analysis tends to take developed regions as the benchmark and reference, and directly compare the economic structure of single and multiple factors, such as production cost and policy, but ignore the structural differences between the different regions [62-64]. The endowment conditions required for industrial integration and expansion of industrial chains are quite different from those for growers who are only engaged in agricultural production. For example, post-production marketing often requires establishing effective connections with the market, while postproduction processing requires increasing post-production capital investment. Growers can be effectively incorporated into the high-value industrial chain $[65,66]$. The policy factors, financial structure, and other superstructure factors are endogenous. Only by adapting the mode of production to the economic base can this reverse action benefit industrial development $[67,68]$. Therefore, understanding of industrial upgrading needs to be started from more fundamental endowment factors and endowment structures and further explore the influence of relevant industrial support factors on industrial development.

In order to make up for the deficiencies of the above research, the new structural economics (NSE) is taken as the theoretical guideline to prove how regions with an underdeveloped agricultural industry learn from the industrial development experience of other regions to realize their ability to upgrade their industry. The theory of new structural economics is proposed by professor Y. Lin [69]. This theory upholds the world outlook of Marxist dialectical materialism and historical materialism. It emphasizes that the economic base decides the superstructure and the reaction of the over structure. NSE could be impacted as a series of strategies for achieving sustainable growth in developing countries by re-examining the shortcoming of the economic crisis and developing structural changes like industrial upgrades [70]. The core aspects of NSE have the following components: First, the organization of an economy's endowments changes as it progresses through stages of advancement. As a result, the best industrial structure for a specific economy will vary depending on its growth phase [71]. Each industrial structure requires a corresponding infrastructure (both "hard" and "soft") to facilitate its operations and transactions [72]. Second, every phase of economic growth is a node on a continuum from a low-income agricultural system to a high-income industrialized economy, rather than a binary between two phases of socioeconomic expansion ("poor" versus "rich" or "developing" versus "industrialized"). The modernization and infrastructural enhancement objectives in developing nations should not be based on those in high-income nations [73]. Third, the market is the fundamental instrument for optimal resources management at each growth phase. However, being a continuous system, economic growth involves technical modernization and accompanying enhancements in "hard" and "soft" infrastructures at each step [74]. Such advancements involve enormous externalities to firms' operational expenses and earnings to principal investment.

Compared with previous studies, this paper may have the following innovation points: (i) We utilized both the micro survey data of farmers and macro data to grasp the development trends of the vegetable industry from the overall and macro perspective, to avoid promoting the effect of macro demand-side factors on the agricultural industry and to view the agricultural development within the scope of coordinated development with nonagricultural industries, which will broaden the research horizon. (ii) Along with growth identification and the facilitation framework (GIFF) of new structural economics [75], we utilized a five-step analysis method to analyze the upgrade of the vegetable industry in Shaanxi. In particular, this study intends to capture and highlight the structural differences in the modes of production between individual enterprises and the whole industry. Moreover, we outline a detailed classification of those differences, which can further improve 
policy-making accuracy. (iii) At present, there are still limited theoretical and policy studies on cross-regional references and learning across the same industries. To the best of our knowledge, this study will be one of the first attempts to trace the industrial transformation and upgrading process using the theory of new structural economics within agricultural economics dimensions. We also test the proposed framework to showcase the path of the vegetable industry transformation and upgrade and put forward specific operational tools in practice. (iv) This study also provides theoretical and policy guidance for analyzing areas with backward agricultural development in China. This paper could provide learning opportunities to other emerging regions, taken from the industrial development experience of advanced areas to accelerate the transformation and upgrade of industrial structure in less developed areas and realize the integration of small growers into modern agriculture.

\section{Theoretical Analysis}

\subsection{Theoretical Framework}

Figure 1 shows the theoretical path of the transformation and upgrade of the vegetable industry. However, an intra-industry upgrade circulation flow chart is presented in this paper to show the above analysis framework more intuitively, covering different decisionmakers and markets of vegetables.

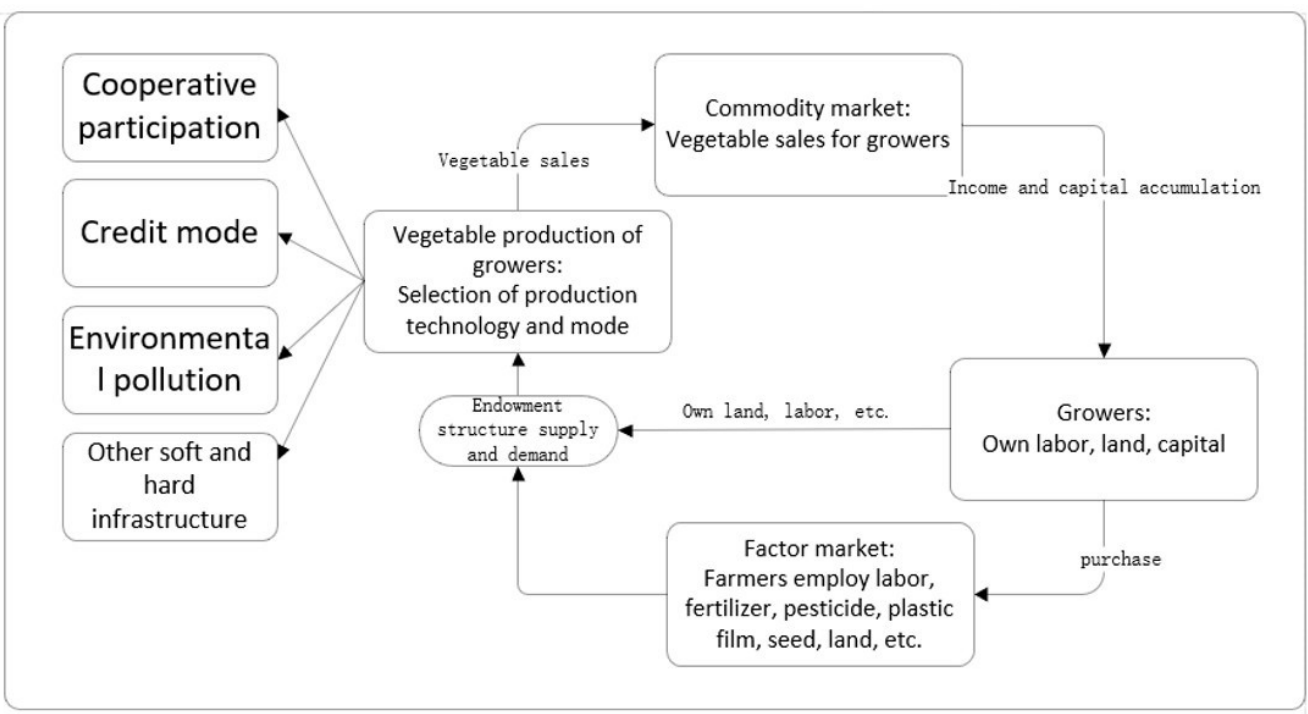

Figure 1. Circulation flow chart of upgrading the vegetable industry.

The industrial upgrade needs to be implemented on the production side, and then the vegetable industry can finally realize its upgrades in the cyclic accumulation of its endowment factors and modes of production. As shown in Figure 1, vegetable growers can use their land and labor to produce vegetables, purchase agricultural materials, or transfer land on the production factor market. The input of capital, land, and other factors in the production process constitutes the supply side of the endowment structure of vegetable production, and, at the same time, specific modes of production also have specific demands on the endowment structure. After that, growers will be able to realize the value of vegetables by selling them in the vegetable market. Thus, growers can receive a certain income from selling vegetables and change their endowment structure employing capital accumulation to upgrade the endowment structure and then promote the constant change of the mode of production. Thus, capital accumulation and upgrading the production mode are finally manifested as upgrading the vegetable industry itself. That is to say, based on matching consumer demand, the contradictory movement between the mode of production and the endowment structure is the core to drive the industrial upgrade from the production side. In addition, soft and hard infrastructures and productive services provided by the government and other industrial organizations are endogenous to the mode of production 
of vegetables, which can play a coordination and service role in the process of any industrial upgrades, driven by the contradictory movement between endowment structure and mode of production. The process of imitation may not be the optimal solution; scientifically justified agricultural development models should be developed based on each region's situations and unique characteristics. However, this may be a very time-consuming and capital-intensive endeavor. Therefore, we have proposed that imitations might be suitable agricultural development options in the study.

\subsection{Five-Step Analysis of the Vegetable Industry Upgrading Process}

In reference to the actual development of the vegetable industry in Shaanxi, a concrete five-step analysis method is presented here. The fundamental theoretical models for analyzing industrial upgrades in different regions in this paper are GIFFs of new structural economics [76], the application model of the facilitation framework for the five industry divisions, and the new structural transformation and upgrading model [77]. The traditional GIFF framework aims at how national economies develop related industries based on the comparative advantages contained in the factor endowment structure. $\mathrm{Xu}$ [76] pointed out that the GIFF framework only provides general methodological guidance for policy research and, even then, only when combined with specific industrial development can pertinent and operable industrial policy guidelines be proposed. The new structural transformation and upgrading framework has further analyzed industrial development issues from the regional, industry, and enterprise levels [78]. Within the same region, micro vegetable growers can be classified according to the factor endowment structure, i.e., several categories within their mode of production, which is a structural level between a single enterprise and the entire industry. In addition, using different from the traditional GIFF and the new structure transformation and upgrading framework, this paper brings the factors from the demand side in the vegetable industry market into the analysis framework. Finally, based on a comprehensive reference to the GIFF framework, the five divisions of industry, and the new structural transformation and upgrading model, a five-step analysis method is established to upgrade and develop the vegetable industry. The logical framework has been shown in Figure 2.
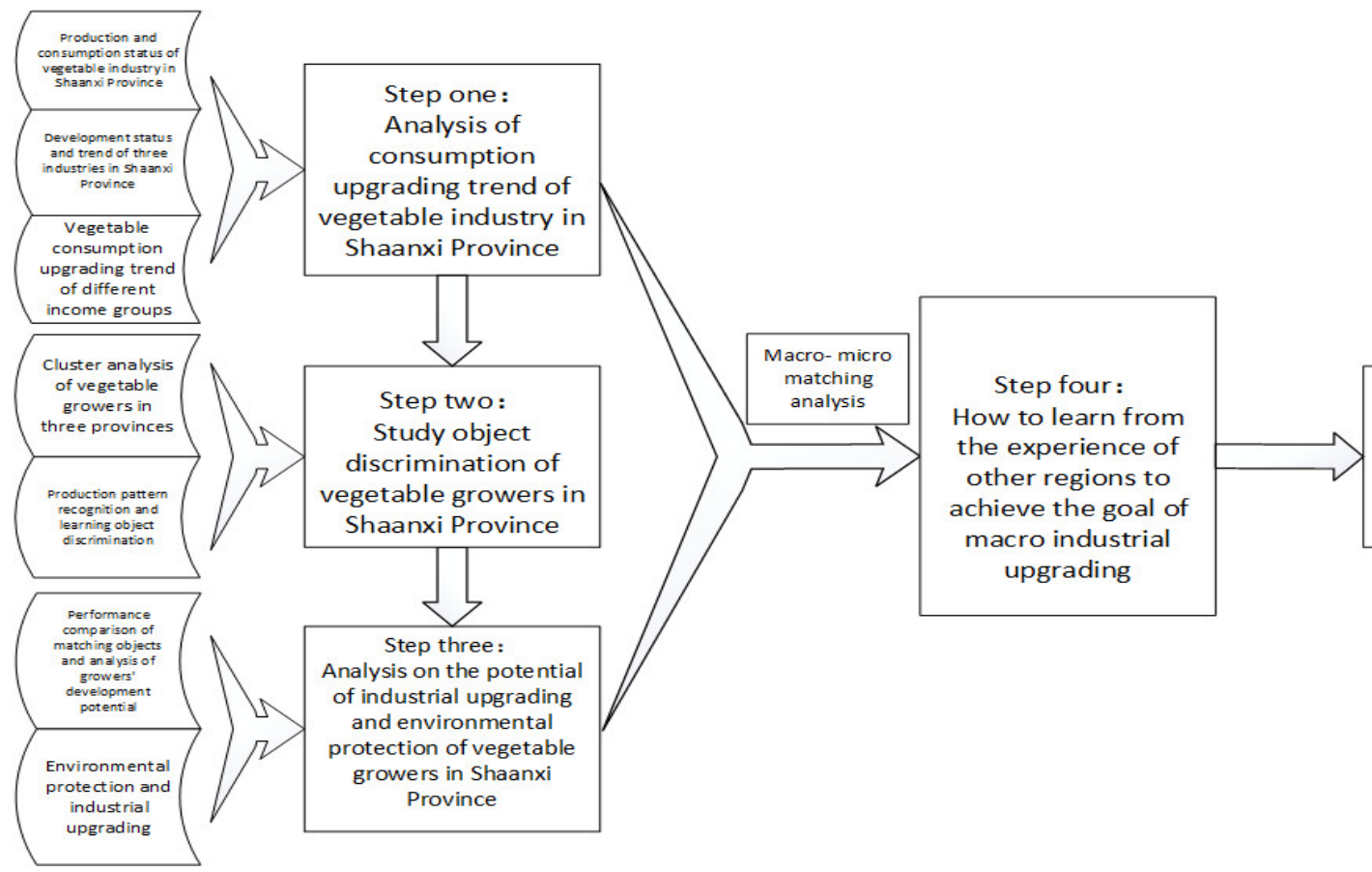

Figure 2. Logical framework diagram of five-step analysis of the upgrade of the vegetable industry in Shaanxi. 
This five-step analysis forms the internal logic before and after analyzing Shaanxi's upgrade of its vegetable industry. Firstly, the trend of consumption upgrading in the vegetable industry in Shaanxi is analyzed based on macro data (step 1). Then, the structural characteristics of the production of vegetable growers in three provinces are analyzed based on microdata to identify the objects that Shaanxi growers can learn from (step 2). The third step is to analyze whether there is room for Shaanxi growers to improve their performance by learning from the development experience of other regions. Next, through the matching analysis of macro demand and micro supply, it is judged whether the potential room for performance improvement can meet the goal of macro industrial upgrading (step 4). The last step is to put forward policy suggestions about how the government can use the situation to promote industrial upgrading based on the current productive services accessible to growers.

\section{Materials and Methods}

\subsection{Data Source}

The macro data in this paper was obtained from the China Statistical Yearbook (2011-2019), Shaanxi Statistical Yearbook (2011-2019), and the statistical yearbook of local regions in Shaanxi (2011-2019). Whereas the micro data was obtained from the survey of production and operation of 1,992 vegetable growers in Shaanxi (605), Hebei (794), and Shandong (593) from August to October 2019. The micro survey mainly involves the essential characteristics of growers' families, family management characteristics, growers' information acquisition, participation in organizations, government support, social capital, risk awareness, etc. The survey was conducted in Shouguang City in Shandong, Langfang City in Hebei, and Jingyang County and Gaoling District (Xi'an) in Shaanxi. Xi'an is Shaanxi's political, economic, and cultural center, with a strong provincial capital effect. Xianyang is adjacent to $\mathrm{X}^{\prime}$ 'an and mainly supplies vegetables to $\mathrm{Xi}^{\prime}$ an and other regions to meet the province's demand for vegetables. Jingyang County (Xianyang) is the largest tomato planting county in the province. According to the statistics of www.sanqin.com (accessed on 12 September 2021), the county has more than 100,000 mu of tomato planting area.

Shandong is a coastal province and is part of the East China region. Shandong has a temperate climate, lying in the transition between the humid subtropical and humid continental zones and has four distinct seasons. Summers are hot and rainy (except for a few coastal areas), while winters are cold and dry. Average temperatures are -5 to $1{ }^{\circ} \mathrm{C}$ ( 23 to $34{ }^{\circ} \mathrm{F}$ ) in January and 24 to $28^{\circ} \mathrm{C}\left(75\right.$ to $\left.82{ }^{\circ} \mathrm{F}\right)$ in July. Annual precipitation is 550 to $950 \mathrm{~mm}$ (22 to $37 \mathrm{in}$ ), the vast majority of which occurs during summer due to monsoonal influences. Shaanxi is a landlocked province. It is officially part of Northwest China and borders the province-level divisions of Shanxi, Henan, Hubei, Chongqing, Sichuan, Gansu, Ningxia, and Inner Mongolia. Due to its large span in latitude, Shaanxi has a variety of climates. Under the Köppen climate classification, the northern parts, including the Loess Plateau, have either a cold arid or cold semi-arid climate, with cold and very dry winters, dry springs and autumns, and hot, humid summers.

Shaanxi is the largest growing area in the northwest region, and its area of protected vegetables reached 2.19 million mu in 2017, with the total yield ranking first in the northwest region [79]. The vegetables grown there are mainly used to satisfy the consumer demand in the province and have become another primary agricultural industry, after animal husbandry and fruit industry in Shaanxi (Data source: Press conference of Strengthening the Level of Facilities and Accelerating the Development of Protected Vegetables in Shaanxi Province on 30 October 2018). In the Shaanxi provincial government report, facility agriculture is also the key development objective of the agricultural portfolio, and the further expansion of facility agriculture is placed in a prominent position (Data source: Government Work Report of Shaanxi in 2020). However, vegetables in Shaanxi have been in a tight equilibrium for a long time and still need to be transported from other places to meet the demand in certain months, reflecting the existing contradiction between supply and demand [80]. The problems involve both quantity and quality. After Shandong, there 
have also been cases of applying high-toxic pesticides in vegetables in Shaanxi (Data source: CCTV News Vegetable growers in Weinan City, Shaanxi apply high-toxic pesticides, but refuse to use pesticides in their own vegetables). Therefore, a green/organic, healthy, and sustainable development mode should be introduced in Shaanxi's vegetable industry to further expand its production capacity. In order to provide theoretical guidance and policy suggestions for upgrading the vegetable industry in Shaanxi, previous research results of agricultural industry upgrading were reviewed first. Moreover, the vegetable variety with the most significant yield in Shaanxi was found to be the tomato. Since tomatoes are planted in all three provinces, and the foothold of our analysis is upgrading the vegetable industry in Shaanxi, the tomato is taken as the representative vegetable for contrastive analysis. Specifically, there are 267, 293, and 354 tomato growers in Shandong, Hebei, and Shaanxi, respectively, totaling 914 farmers. However, in this study we do not intend to collect data from any specific criteria, such as conventional or organic base, rather we categorized them by farming scale, labor input, and capital input.

Hebei is a coastal province of the People's Republic of China and is part of the North China region. Hebei has a monsoon-influenced humid continental climate, with cold, dry winters, and hot, humid summers. Temperatures average between -16 and $-3{ }^{\circ} \mathrm{C}$ ( 3 to $27^{\circ} \mathrm{F}$ ) in January and 20 and $27^{\circ} \mathrm{C}\left(68\right.$ to $\left.81^{\circ} \mathrm{F}\right)$ in July; the annual precipitation ranges from 400 to $800 \mathrm{~mm}$ (16 to $31 \mathrm{in}$ ), concentrated heavily in summer. Hebei is the province with more suitable factor endowments for vegetable production [81]. The cultivation tactics in use in vegetable production in the Hebei province are well superior to those in use in the Shaanxi Province [82]. Moreover, the Hebei and Shaanxi provinces are quite similar in terms of climate and geographical characteristics, which may also assist to enable the transfer of production patterns in Shaanxi.

\subsection{Adopted Methodology}

This paper classified growers in different regions using SPSS software and a twostep clustering method based on the Bayesian information criterion (BIS). The benefit of using a clustering analysis is that continuous variables and classified variables can be analyzed simultaneously, and the number of categories can be determined automatically. Hence, the automatic classification method is adopted for clustering analysis. VIF (Variance Inflation Factor) value is measured first to analyze whether there is multicollinearity between variables before the two-step clustering analysis. In the analysis with per mu yield of tomatoes, net income per mu of tomatoes, and unit selling price of tomatoes as the explained variables, the results show that the average VIF values are 1.21 and 1.17, respectively, and the VIF value between explanatory variables is less than 2, indicating that there is no significant collinearity.

The two-step clustering analysis can automatically set up the classifications according to the log-likelihood estimation and combine multiple indexes. The structural difference and endogeneity analysis should include a systematic comparison among various factors of growers, and clustering analysis is a general method to classify growers with similar characteristics. Previous simulation studies have shown that the two-step clustering method can effectively synthesize information and determine the number of clusters. The two-step clustering method does not determine the number of clusters based on a single index but comprehensively considers BIC (Bayesian Information Criteria) value and BIC value change and eventually determines the optimal number of clusters [83]. In the selection of clustering indexes, the endowment factors (capital, land, and labor) in the factor endowment structure of new structural economics and the planting performance (price, per mu yield, and net income per $\mathrm{mu}$ ) are taken as the clustering indexes in order to reflect the differences between different modes of production and their performance based on the factor endowment structure.

Clustering analysis is a multidimensional quantitative analytical tool for classifying research objects based on their attributes [84]. The two-step clustering algorithm can be used to obtain judgment information about various clustering figures as well as other fre- 
quency tables. The approach utilizes a probability proximity metric to manage categorized and longitudinal data, assuming that parameters in the cluster model are consistent [85]. Furthermore, within the method, all constant factors are expected to have a normal (Gaussian) distribution, whereas each variable has a multivariate regression allocation. This study utilized the following stages to perform the two-step cluster analysis as suggested by Benassi et al. [86]. In the first step (pre-clustering), a sequential approach is used to pre-cluster the cases based on the definition of dense regions in the analyzed attribute space. In the second step (clustering), the pre-clusters are statistically merged in a stepwise way until all clusters are in one cluster. The modeling assumptions are derived by the dependent probabilities of reporting each response for each manifest variable in a particular category, and they are evaluated as the fraction of observations in each latent class [87]. Interestingly, this method can be used to fit both ordinal and observable factors. The clustering algorithms' external reliability was confirmed by evaluating clusters (independent variable) on a separate number of psychological tests (dependent variables) as suggested by Kent et al. [88]. The sample was divided into subsamples to determine the clustering strategy's internal consistency. Cohen's Kappa measurement was evaluated to assess the step of arrangement among the clusters' consignments for each variable when considered in the cross-diagnostic sample and within the single diagnostic subsample.

\subsection{Variable Selection}

\subsubsection{Factor Endowment Structure}

The endowment factors in the factor endowment structure of new structural economics mainly include capital, labor, land, and natural resources. Farmers' capital usually refers to economic capital and human capital, economic capital is usually expressed by the price of farmers' housing, representing the fixed stock of farmers. Among them, capital can be further divided by three sets of indicators. The first set is the capital input of modern means of production such as seedlings, fertilizers, pesticides, and water charges per mu (the price per mu of those inputs); the second set is the capital input of agricultural machinery per $\mathrm{mu}$; the third set is the unit price of vegetable greenhouses. Labor input is expressed in the total amount of household labor and employed labor input per mu of tomato. Land refers to the land farmed by farmers. Finally, land input is expressed by three indicators: total family land area, vegetable planting area, and tomato planting area.

\subsubsection{Tomato Planting Performance}

In this paper, tomato quality is represented by the sale price of a tomato, which is taken as the grower's planting performance and net income per mu and per mu yield. Price is determined by value first, and the actual price is eventually formed by supply and demand. The sale price of tomatoes represents the capital input and embodies the labor cost of growers in this course. A higher price usually quantified better quality, so price is used to represent quality. Other macro data variables such as total vegetable yield, per mu yield of vegetable, investment index of fixed assets in Shaanxi, urban and rural income, and other indexes are obtained from the China Statistical Yearbook (2011-2019), the Shaanxi Statistical Yearbook (2011-2019), and the statistical yearbooks of local regions in Shaanxi (2011-2019).

\section{Results}

\subsection{Production Status and Trend of Consumption Upgrading of the Vegetable Industry in Shaanxi}

In the first step of the five-step analysis, the production status and trend of consumption upgrading of vegetable growers in Shaanxi were analyzed from three aspects. First, the current situation of vegetable production and consumption in Shaanxi was analyzed based on macro data; then, the development status and trend of the three industries that affect consumption from the income perspective were analyzed; finally, the income status and trend of vegetable consumption of different income brackets were analyzed from the perspective of income heterogeneity. 


\subsubsection{Current Vegetable Production and Consumption Characteristics in Shaanxi}

The factors that promote the continuous improvement of the total vegetable yield in Shaanxi are the increase per mu of yield and total planting area. According to the Shaanxi Statistical Yearbook (2011-2019), the vegetable yield in Shaanxi has steadily increased from $12,944,900$ tons in 2010 to $18,084,400$ tons in 2018, with an average annual growth rate of $4.96 \%$. The yield growth is influenced by the expansion of the planting area and the increase of per mu yield. In 2010, the per mu yield of vegetables in Shaanxi was only $1962.39 \mathrm{~kg} / \mathrm{mu}$; this increased to $2435.32 \mathrm{~kg} / \mathrm{mu}$ in 2018, with an average annual growth rate of $3.01 \%$. The planting area increased from 6,596,550 $\mathrm{mu}$ to $7,425,900 \mathrm{mu}$, with an average annual growth rate of $1.57 \%$. The key driving factor for the increase in total yield was the increase per mu yield and planting area; the growth rate was greater than the latter.

The consumption per capita in the province is increasing but is still lower than the average consumption of the whole country, Shandong, and Hebei. The per capita vegetable consumption in Shaanxi increased from $63.1 \mathrm{~kg}$ in 2013 to $83.5 \mathrm{~kg}$ in 2018, with an average annual growth rate of $4.08 \%$. However, although significant progress has been made, Shaanxi's per capita vegetable consumption is $15.09 \%, 11.13 \%$, and $14.37 \%$ lower than the average level of the whole country, Hebei, and Shandong, respectively.

The vegetable industry in Shaanxi is an essential industry and a catching-up industry among the five industries in new structural economics. If the average per mu yield of vegetables is taken as the proxy index for the industrial development level, the per mu yields of vegetables in Shandong and Hebei in 2018 are 51.57\% and 79.15\% higher than Shaanxi, respectively. Therefore, according to the division basis for the five industries in new structural economics [69], it can be preliminarily determined that the vegetable industry in Shaanxi is still in the catching-up stage at the forefront of industrial development, and there is still room for an increase in per mu yield.

\subsubsection{Industrial Upgrading Trends on the Consumption Side}

For the vegetable industry in Shaanxi, the upgrading trend on the consumption side can be analyzed from two perspectives of total quantity and quality. First, vegetables are necessary agricultural products that meet our basic needs. Second, according to the broad experience of different developed regions in China and other developed countries, the per capita consumption will remain stable when it enters a particular stage, and then the demand for high-quality vegetables will be more robust $[3,89]$. So, what is the development stage of vegetable consumption in Shaanxi, and what promotes the continuous increase in vegetable consumption and yield? Is there a trend to further increase the quantity or improve the quality? The direct factors influencing consumption include income level, urbanization, population growth, etc.; the vegetable industry's development status and consumption trend are further analyzed based on macro influencing factors.

\subsubsection{Development of Three Industries and Vegetable Consumption}

The characteristics of vegetable consumption are the final result of economic development, but industrial development can become an intermediate hub to understand the relationship between capital investment, accumulation, and vegetable consumption. This is because the consumption level and characteristics of residents in Shaanxi depend on the income level, while the income increase is dependent on the development of related industries in which workers engaged. Moreover, the direct factor promoting industrial development is an industrial investment and composition manifested in labor transfer between industries and urbanization. Hence, it is necessary to further analyze the future trends of income change and vegetable consumption from industrial investment and population transfer perspective.

The three industries in Shaanxi are gradually upgraded and optimized as driven by investment, and there is still room for optimization. From 2010 to 2018, the proportion of total investment that is invested in the tertiary industry is significantly higher than other industries (Figure $3 \mathrm{~A}$ ), and the proportion of the tertiary industry in the gross national 
product increased from $36 \%$ in 2010 to $43 \%$ in 2018 . The proportion of investment in the secondary industry gradually decreased from 54\% in 2010 to $50 \%$ in 2018, and investment in the primary industry decreased from 10\% in 2010 to $7 \%$ in 2018 (Figure 3B). According to the general development pattern of the three industries, the proportion of the output value of the secondary industry in Shaanxi is still high, and that of the primary industry will continue to decrease. There is room for further development of the tertiary industry so that the industrial structure will be further improved. Industrial development also tends to cause labor transfer between industries. Since 2010, the proportion of the total population that works in the primary industry has gradually decreased from $41.27 \%$ in 2010 to $38.05 \%$ in 2018 , but its output value only accounts for $7 \%$ of the total output value. The proportion of the employed population in the secondary industry decreased from $27.05 \%$ in 2010 to $15.93 \%$ in 2018 , and the tertiary industry gradually increased from $31.67 \%$ in 2010 to $37.95 \%$ in 2018 (Figure 4A). Therefore, the tertiary industry has gradually become a significant industry that receives employed population. The labor productivity of the primary industry in Shaanxi is lower than that of the secondary and tertiary industries (Figure 4B).
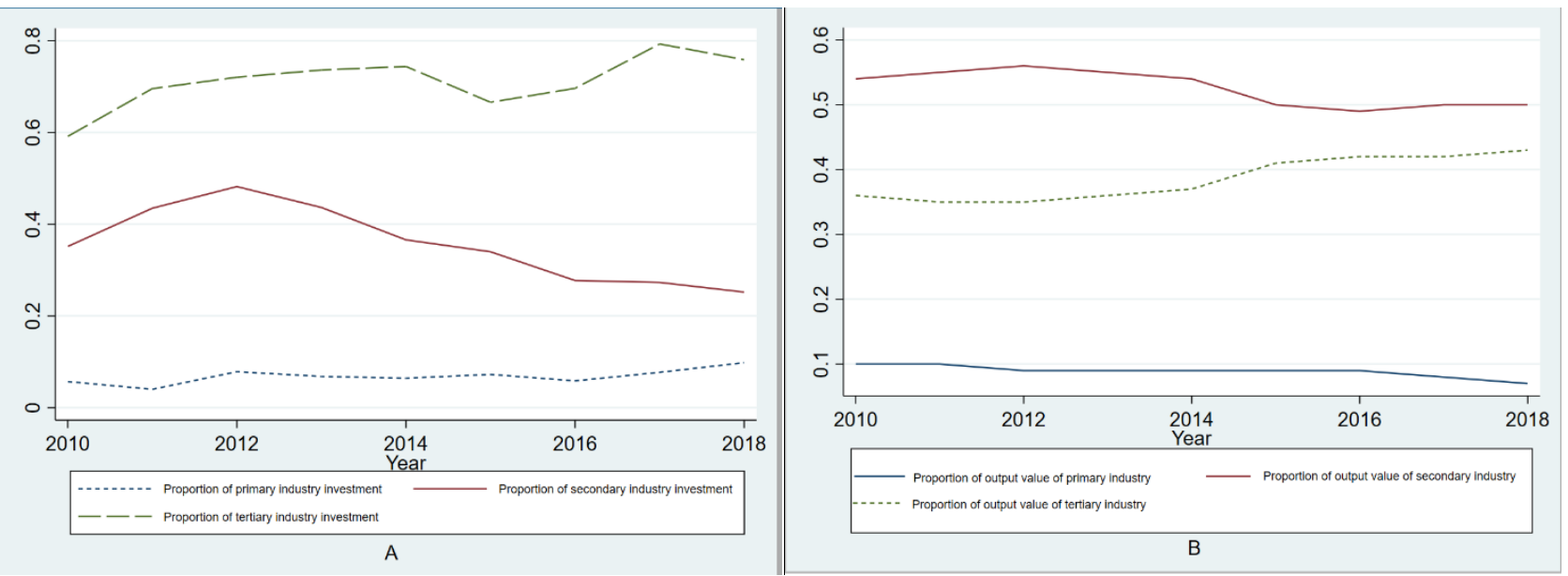

Figure 3. Proportion of investment, (A) denotes the proportion of investment in the tertiary industry in Shaanxi, and (B) denotes the proportion of investment in secondary industry in Shaanxi.
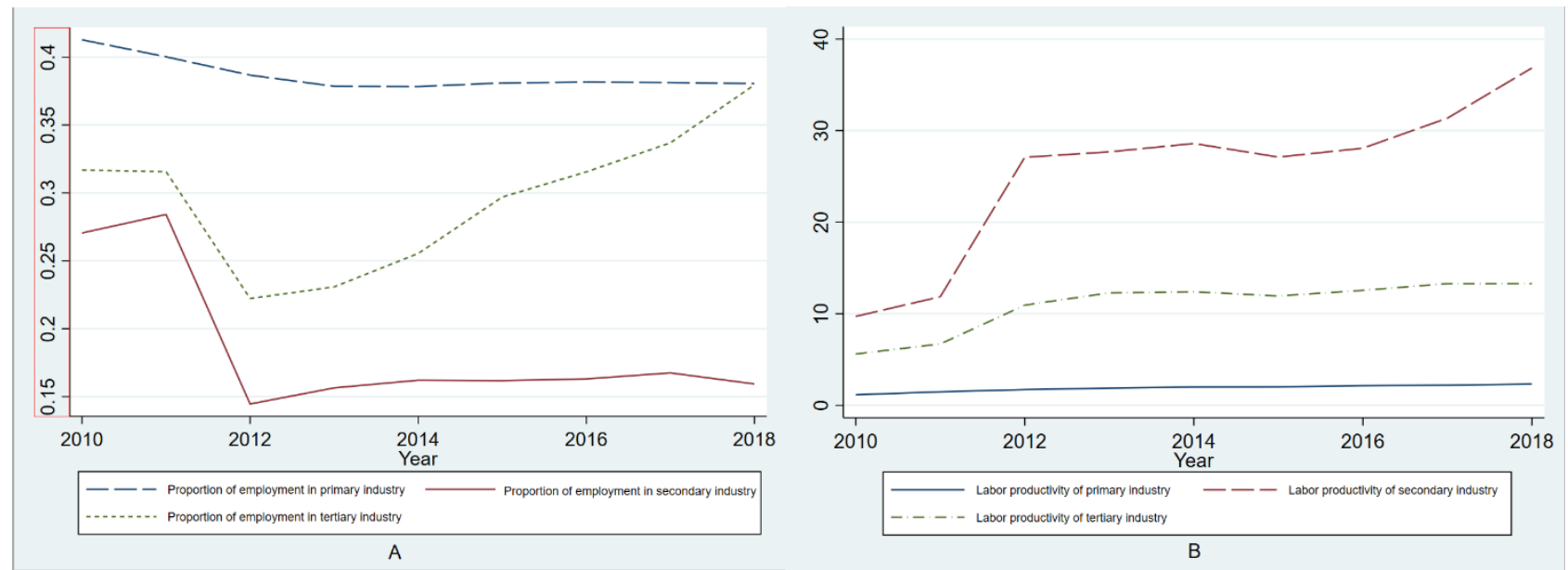

Figure 4. (A) Proportion of employed population in the tertiary industry in Shaanxi and (B) Labor productivity of three industries in Shaanxi.

Consequently, with the continuous development of the tertiary industry, the labor force will shift from the primary industry with lower labor productivity to the tertiary industry. The improvement of labor productivity will positively increase the income of 
such a labor force. The total vegetable consumption in Shaanxi will increase along with the income increase. With the increase in income, there is still room for improved per capita consumption, increasing the total demand. On the whole, Shaanxi is still in the stage of increasing total vegetable consumption. The income gap between urban and rural areas, different regions, and different brackets, as well as these factors' influence on vegetable consumption is further explored to analyze the structural difference of residents' income levels and their influence on vegetable consumption.

\subsection{Income Status and Vegetable Consumption Upgrading Trend between Urban and Rural Areas and Different Regions}

There is disequilibrium in residents' income and vegetable consumption in Shaanxi. Urban high-income households have higher requirements for vegetable quality. Due to data availability, the year 2017 was taken as an example, as shown in Table 1.

Table 1. Disposable income and vegetable consumption of different income brackets in Shaanxi in 2017.

\begin{tabular}{cccccccc}
\hline & & $\begin{array}{c}\text { Grand } \\
\text { Average }\end{array}$ & $\begin{array}{c}\text { Low- } \\
\text { Income } \\
\text { Household }\end{array}$ & $\begin{array}{c}\text { Low-to- } \\
\text { Medium- } \\
\text { Income } \\
\text { Household }\end{array}$ & $\begin{array}{c}\text { Medium- } \\
\text { Income } \\
\text { Household }\end{array}$ & $\begin{array}{c}\text { Medium-to- } \\
\text { High- } \\
\text { Income } \\
\text { Household }\end{array}$ & $\begin{array}{c}\text { High- } \\
\text { Income } \\
\text { Household }\end{array}$ \\
\hline \multirow{2}{*}{ Rural } & Disposable income (RMB) & $10,264.50$ & 2222.70 & 6795.50 & 9647.70 & $13,562.80$ & $22,889.20$ \\
areas & Fresh vegetable (KG) & 44.70 & 35.40 & 38.80 & 43.00 & 50.30 & 61.20 \\
& Expenditure (RMB) & 224.20 & 182.50 & 189.60 & 214.70 & 256.70 & 302.60 \\
Urban & Disposable income (RMB) & $30,810.30$ & $12,890.10$ & $22,185.60$ & $30,164.30$ & $39,094.90$ & $61,034.20$ \\
areas & Fresh vegetable (KG) & 103.50 & 82.00 & 100.00 & 110.10 & 118.20 & 116.50 \\
& Expenditure (RMB) & 546.08 & 410.17 & 510.17 & 578.97 & 615.33 & 683.33 \\
\hline
\end{tabular}

There is an apparent difference between urban and rural areas in Shaanxi; the per capita income of rural residents is only $33.32 \%$ of that of urban residents. In 2017 , the disposable income of low-income households among rural residents was only $9.71 \%$ of that of high-income households, and the disposable income of medium-income households was less than RMB 10,000. Among urban residents, the disposable income of low-income households is only $21.12 \%$ of that of high-income households. As the income of rural residents from different brackets increases, the consumption of fresh vegetables shows an apparent increasing trend. Urban residents also show similar trends. This indicates that, with the improvement of income level, the per capita consumption of vegetables will also increase. However, among urban residents, the expenditure per kilogram of vegetables is 5.87 Yuan for high-income households and 5.21 Yuan for medium-to-high income households, where the expenditure is increased while the absolute quantity slightly decreases. That is to say, with the increase of income, high-income households tend to have higher requirements for vegetable quality, such as ecologically and organically produced vegetables. Although there are no detailed statistics to explain the number and proportion of residents in each income bracket, the significant income gap between different income groups can be further understood by analyzing the per capita income in different regions in Shaanxi (Table 2). 
Table 2. Disposable income of residents and number of residents living in cities and districts in Shaanxi.

\begin{tabular}{|c|c|c|c|c|c|}
\hline & \multicolumn{2}{|c|}{ Disposable Income of Urban Residents } & \multicolumn{2}{|c|}{ Disposable Income of Rural Residents } & \multirow{2}{*}{$\begin{array}{c}\text { Resident } \\
\text { Population in } 2018\end{array}$} \\
\hline & 2018 & 2017 & 2018 & 2017 & \\
\hline Shaanxi & $33,319.00$ & $30,810.00$ & $11,213.00$ & $10,265.00$ & 3864.40 \\
\hline $\begin{array}{l}\text { Xi'an City } \\
\text { Yangling }\end{array}$ & $38,729.00$ & $35,837.00$ & $13,286.00$ & $12,190.00$ & 1000.37 \\
\hline $\begin{array}{l}\text { Demonstration } \\
\text { Zone }\end{array}$ & $35,193.00$ & $32,596.00$ & $12,392.00$ & $11,320.00$ & 20.93 \\
\hline Xianyang City & $33,364.00$ & $30,874.00$ & $10,893.00$ & 9985.00 & 436.61 \\
\hline Yan'an City & $32,226.00$ & $29,849.00$ & $10,786.00$ & 9878.00 & 225.94 \\
\hline Baoji City & $31,802.00$ & $29,402.00$ & $11,936.00$ & $10,921.00$ & 377.10 \\
\hline Yulin City & $31,317.00$ & $28,954.00$ & $12,034.00$ & $11,031.00$ & 341.78 \\
\hline Weinan City & $31,133.00$ & $28,757.00$ & $11,655.00$ & $10,655.00$ & 532.77 \\
\hline Hanzhong City & $30,380.00$ & $28,010.00$ & $10,088.00$ & 9231.00 & 343.61 \\
\hline Tongchuan City & $29,996.00$ & $27,707.00$ & 9289.00 & 8507.00 & 80.37 \\
\hline Ankang City & $24,977.00$ & $23,073.00$ & 9504.00 & 8688.00 & 266.89 \\
\hline Shangluo City & $23,491.00$ & $21,678.00$ & 9112.00 & 8322.00 & 238.02 \\
\hline
\end{tabular}

Shaanxi is characterized by unbalanced regional economic development, so one of the main driving forces for the development of the vegetable industry is to effectively satisfy the growing demand of different income groups for vegetables, especially middle-lowincome groups. According to the statistics from 2018 (Table 2), only Xi'an, the Yangling Demonstration Zone, and Xianyang, which account for $37.73 \%$ of the total population, had higher than the average level in per capita income. In order to meet the demand for agricultural products for the urban development of Xi'an, the Yangling Demonstration Zone (under the government of Xianyang) and Xianyang have become the first export places of agricultural products in Shaanxi with prominent suburban agricultural characteristics. In Southern Shaanxi, the Qinba Mountains area was once a concentrated poverty-stricken area designated by the state, mainly covering three cities, i.e., Hanzhong, Ankang, and Shangluo. The area's population accounted for $21.97 \%$ of the total residents in Shaanxi and is now up to $24.03 \%$, together with the population of Tongchuan. The population proportion of other cities, including Yan'an, Baoji, Yulin, and Weinan, is $38.24 \%$. Therefore, although the city has a specific demand for high-quality vegetables, the large-, middle-, and low-income groups accounts for $62.27 \%$ of the total population, except for Xi'an, Xianyang, and the Yangling Demonstration Zone, which constitutes the leading consumer group for the growth of vegetable consumption. Along with economic development, this group still has a considerable space to increase its income, which will impose higher requirements on the supply of the vegetable industry (in both quantity and quality).

However, they cannot be applied to specify the matching between the vegetable industry and consumption side according to micro growers or to meet the macro consumption trend through industrial upgrading. According to the macro analysis of the vegetable industry, the vegetable industry in Shaanxi is still in the catching-up stage relative to the eastern region as a whole. Therefore, structural analysis on the production side is carried out in the next part section of this paper on the micro survey data of cross-regional vegetable growers (taking tomato growers as an example).

\subsection{Structural Analysis on the Production Side of Micro Tomato Growers in Shaanxi, Hebei, and Shandong}

The analysis is conducted according to the second step of the five-step analysis method: identifying learning objects. Firstly, clustering analysis is made on the factor endowment structure and performance of micro growers in different regions. Then the characteristics of different categories are summarized to find out the categories of growers with similar characteristics in other regions that can be compared. 


\subsection{Identify Matching Objects}

The tomato planting industry in different regions is in different stages of development, and there are structural differences and similarities between regions and between growers in those regions. As shown in Table 3, growers' production in Shandong and Hebei can be divided into two categories. Through the comparison between the two categories of growers in Shandong, it is found that the main characteristics of category one tomato growers in Shandong are "small tomato planting area + high labor input + high capital input (both greenhouse and machinery input are higher than those of category two growers)", and the main characteristics of category 2 are "large planting area + low labor input + low capital input." The absolute values of physical capital, machinery capital, and labor input of category two growers are lower than those of category one growers, but the per mu yield and net income per mu are higher than those of category one growers. This is because, after a certain threshold of physical capital input, physical capital will no longer be the main driving force of industrial upgrading, and category two growers have entered the stage driven by natural capital, financial capital, physical capital, and social capital. Category two growers in Hebei and Shaanxi are still far lower than those in Shandong, regarding physical capital and machinery capital input. Therefore, growers in Hebei and Shaanxi are still at the stage in which technological upgrades are driven by capital input, returns to scale increase progressively, and capital and data factors are in a secondary and auxiliary position.

Table 3. Clustering analysis results of factor endowment structure and performance in Shaanxi, Hebei, and Shandong.

\begin{tabular}{|c|c|c|c|c|c|c|c|}
\hline \multirow[b]{2}{*}{ Categories } & \multicolumn{3}{|c|}{ Shaanxi } & \multicolumn{2}{|c|}{ Hebei } & \multicolumn{2}{|c|}{ Shandong } \\
\hline & Category 1 & Category 2 & Category 3 & Category 1 & Category 2 & Category 1 & Category 2 \\
\hline Proportion & $42.6 \%$ & $32.5 \%$ & $24.9 \%$ & $53.1 \%$ & $36.9 \%$ & $57.3 \%$ & $42.7 \%$ \\
\hline Tomato planting area (mu) & 2.14 & 1.69 & 3.99 & 1.32 & 3.36 & 2.11 & 4.08 \\
\hline Vegetable planting area (mu) & 4.10 & 2.34 & 7.04 & 1.89 & 5.08 & 2.27 & 3.38 \\
\hline Total planting area $(\mathrm{mu})$ & 5.37 & 4.15 & 8.46 & 6.07 & 7.06 & 2.57 & 5.33 \\
\hline Per mu labor input of tomato (day) & 207.20 & 439.42 & 148.35 & 492.75 & 180.46 & 357.72 & 207.44 \\
\hline $\begin{array}{l}\text { Unit price of vegetable } \\
\text { greenhouse }\end{array}$ & $24,322.57$ & $36,097.42$ & $61,397.27$ & $26,620.16$ & $16,871.68$ & $28,845.37$ & $50,700.25$ \\
\hline Per mu machinery input (RMB) & 851.09 & 1144.88 & 868.54 & 911.82 & 486.00 & 3753.91 & 1667.82 \\
\hline Means of production (RMB) & 4865.35 & 7540.48 & 4716.86 & 6953.82 & 3530.09 & $11,141.52$ & 9955.77 \\
\hline Net income per mu of tomato (RMB) & 5844.86 & $19,269.00$ & $10,634.61$ & $19,016.23$ & $12,024.59$ & $30,094.57$ & $49,647.11$ \\
\hline Per mu yield of tomato (KG) & 4554.58 & 6234.4 & 5401.4 & 7204.98 & 5316.55 & 10842 & $14,957.90$ \\
\hline $\begin{array}{l}\text { Normal unit selling price of } \\
\text { vegetables (Yuan/KG) }\end{array}$ & 2.6 & 4.44 & 2.98 & 4.56 & 3.9 & 3.92 & 4.04 \\
\hline
\end{tabular}

Note: Net income per mu of tomato: (sales-cost of goods sold).

The mode of production of growers in Hebei can be divided into two categories. Through the comparison between the two categories of growers, it is found that the main characteristics of category one growers are "small tomato planting area + high labor input + high capital input (both greenhouse and machinery input are higher than those of category two growers)", and the main characteristics of category 2 are "large planting area + low labor input + low capital input." Therefore, the prominent characteristic of category one growers is intensive and meticulous cultivation, with both net incomes per mu and per mu yield higher than category two growers. In contrast, category two growers cannot complete intensive cultivation due to their large planting areas and insufficient input for effective labor and capital. The analysis in this paper focuses on how growers in Shaanxi learn from the development experience of other regions to achieve industrial upgrading, so this paper does not elaborate on the issues related to the industrial upgrading of growers in Hebei.

Based on the differences and similarities of industrial structures in different regions, tomato growers in Shaanxi can learn from growers in Hebei instead of Shandong. Tomato growers in Shaanxi can be divided into three categories with different production structures. By analyzing the characteristics of each category and comparing the tomato planting char- 
acteristics in other regions, these growers can find more suitable learning objects for their developmental stages and structural characteristics. For example, category one growers are characterized by "medium planting area + the medium number of labors + lowest capital input (greenhouse input is much lower than other growers, and the input of machinery and means of production are similar to category three growers)"; category two growers are characterized by "minimum planting area + largest number of labors + medium capital input (machinery input is the highest, greenhouse unit price is the middle, and input of means of production is the highest)", and category three growers are characterized by "largest planting area + minimum labor input + highest capital input (means of production and machinery input are similar to category one growers, and unit price of the greenhouse is the highest)." Therefore, by comparing the production characteristics of growers, it is found that category two growers in Shaanxi and category one growers in Hebei have similar factor input characteristics, i.e., the intensive cultivation model of small planting areas and high capital input. In contrast, category three growers in Shaanxi and category two growers in Hebei have similar factor input characteristics, i.e., large planting area and low labor and capital input. Therefore, category 2 and 3 growers in Shaanxi and Hebei are comparable.

\subsection{Comparison of the Planting Performance of Matching Objects}

Category 2 and 3 growers in Shaanxi can learn from the development experience of growers in Hebei in terms of per mu yield and quality improvement. According to the third step of the five-step analysis method, the similarity of the mode of production is only the first step of the analysis, i.e., identifying the comparable objects and whether an experience worth learning can be found through performance comparison. Performance can be compared from three aspects: per mu yield, net income per mu, and unit selling price. The unit price of greenhouses for category 2 and 3 growers in Shaanxi is significantly higher than that for Hebei's category 1 and 2 growers. Therefore, greenhouses as an infrastructural input are not the main restraining factor for industrial upgrading at this stage. Other major input factors may become significant constraint factors for category 2 and 3 growers in Shaanxi. The net income per mu and unit selling price of category one growers in Hebei are similar to those of category two growers in Shaanxi, but their yield is $15.57 \%$ higher than that of category two growers in Shaanxi. In addition, these two categories of growers have similar modes of production. Under the condition that capital and labor input does not require excessive adjustment, category two growers in Shaanxi have a potential of $15.57 \%$ for improving per mu yield by improving crop management and rational use of means of production. The potential room for improvement of per mu yield here emphasizes the potential for improving per mu yield, and the room for improvement of price below is similar. The per mu yield of category three growers in Shaanxi is higher than that of category two growers in Hebei, but the net income per mu is lower than that of the related growers in Hebei because the unit selling price of category three growers in Shaanxi is only $76.41 \%$ of that of category two growers in Hebei. Therefore, by improving the vegetable quality, there is room for category three growers in Shaanxi to further improve tomatoes' unit selling price. There is no specific reference object for category one growers in Shaanxi, but regional internal learning and references are suitable development models. For example, category one growers' machinery production and labor market share input are higher than that of category three growers, but the per mu yield, net income, and unit selling price of vegetables are lower than those of category three growers. Category 1 growers should increase the input in greenhouse construction and improve their management level, so there will be a large room for improving the yield and quality of their vegetables.

In addition, it is also worth noticing that the labor input of growers in Shaanxi of the same planting pattern is lower than that of growers in Hebei. Therefore, the per mu machinery input of growers in Shaanxi is also higher than that of growers of the same category in Hebei, highlighting the impact of labor outflow on the vegetable industry. 


\subsection{Analysis of the Industrial Upgrading Path for Different Categories of Tomato Growers in Shaanxi}

By learning from the development experiences of growers in Hebei, those in Shaanxi can match the macro consumption trend mentioned above. According to the fourth step of the five-step analysis method, the potential for tomato planting in Shaanxi to realize macro growth objectives by drawing on the development experience of other regions is analyzed. Macro analysis has shown that it is necessary to continuously improve vegetable yield and quality in Shaanxi. The three categories of growers in Shaanxi can achieve specific improvements in quantity and quality, but their paths are different. Specifically, category two growers have the best tomato quality, and they can further improve their per mu yield by drawing on the development experiences of category one growers in Hebei. On the other hand, category three growers have a large tomato planting area, and they can improve their product quality and increase their unit selling price and income by learning from the development experience of category two growers in Hebei. According to the above analysis, it is found that category 2 and 3 growers in Shaanxi are at the forefront of industrial development, and there is room for them to achieve macro development goals by referring to the development experience of growers in Hebei.

Category 1 growers in Shaanxi can improve their planting performance and achieve industrial upgrades by drawing lessons from other regions. Category 1 growers in Shaanxi account for the highest proportion in the micro survey and have the lowest selling price. These growers and category three growers can well match the demand for tomatoes of low-to-medium income households. As the demand increases in the future, these growers need to increase greenhouses, production, and management input while improving per mu yield and vegetable quality. Internal learning and references in the region are the leading measures for these growers to improve their planting performance.

The analysis of industrial upgrading on the production side has fully demonstrated the orientation and path of upgrading for different categories of growers. The development of the vegetable industry cannot be separated from the support of many industrial organizations and the government. The following section will analyze a series of productive services provided by vegetable industrial organizations and the government.

\subsection{Participation of Tomato Growers in Productive Services}

The fifth step of the five-step analysis mainly analyzes the participation of growers in productive services that are endogenous to the mode of production. Due to the different forms of industrial organizations in different regions, this paper focuses on the productive services provided by various industrial organizations and soft and hard infrastructure. Through field survey, it is found that the primary productive services include a unified supply of fertilizers, pesticides, and other agricultural materials the unified management and procurement of vegetables by industrial organizations; and government provision of vegetable subsidies, publicity and promotion services, bank credit, post-production refrigeration, etc. Others are expressed as the participation ratio of different categories of growers in production services except for credit in specific amounts.

The productive services participated in by growers in Shaanxi and Hebei have certain similarities. Growers in Shaanxi and Hebei are similar in structure on the production side, so the characteristics of their participation in productive services are also similar. As can be seen from Table 4, the participation ratio of growers in Shaanxi and Hebei in cooperatives, unified supply of means of production, unified management, and unified procurement is low, which is determined by the actual situation of vegetable production. Vegetable production is a labor-intensive industry, in which the actual situation of individual growers greenhouses is often very different from other growers' greenhouse situations, with great flexibility. Growers in Shaanxi and Hebei mainly purchase agricultural materials from agricultural material shops. The adequate competition among numerous agricultural material shops has set the price of agricultural materials at a very competitive price. As such, there is no value for industrial organizations such as cooperatives to provide and manage unified services. Through interviews with local growers, the authors found that 
cooperatives in Shouguang city have previously carried out the unified procurement of means of production. However, due to the different production conditions of each household during vegetable planting, growers often choose the means of production such as fertilizers and pesticides suitable for their gardens according to their own experience, so growers may not choose the unified procurement of agricultural materials with low price if it is not suitable for their gardens. Instead, agricultural materials are supplied by agricultural material shops or by direct cooperation with manufacturers.

Table 4. Participation of tomato growers in productive services.

\begin{tabular}{|c|c|c|c|c|c|c|c|c|}
\hline & $\begin{array}{c}\text { Organizational } \\
\text { Participation } \\
(\%)\end{array}$ & $\begin{array}{l}\text { Unified } \\
\text { Supply } \\
(\%)\end{array}$ & $\begin{array}{c}\text { Unified } \\
\text { Management } \\
(\%)\end{array}$ & $\begin{array}{c}\text { Unified } \\
\text { Procurement } \\
(\%)\end{array}$ & $\begin{array}{c}\text { Government } \\
\text { Promotion } \\
\text { and } \\
\text { Training (\%) }\end{array}$ & $\begin{array}{c}\text { Vegetable } \\
\text { Subsidies } \\
(\%)\end{array}$ & $\begin{array}{l}\text { Credit } \\
\text { Loan } \\
\text { (RMB) }\end{array}$ & $\begin{array}{c}\text { Post- } \\
\text { Production } \\
\text { Refrigeration } \\
\quad(\%)\end{array}$ \\
\hline \multicolumn{9}{|l|}{ Shaanxi } \\
\hline Category 1 & 11 & 1 & 0 & 5 & 25 & 9 & 4589.13 & 3 \\
\hline Category 2 & 11 & 2 & 0 & 4 & 25 & 8 & 8520.54 & 9 \\
\hline $\begin{array}{c}\text { Category } 3 \\
\text { Hebei }\end{array}$ & 8 & 2 & 0 & 2 & 16 & 5 & $13,050.78$ & 6 \\
\hline Category 1 & 12 & 5 & 0 & 6 & 36 & 9 & 3389.63 & 18 \\
\hline $\begin{array}{l}\text { Category } 2 \\
\text { Shandong }\end{array}$ & 12 & 7 & 3 & 5 & 37 & 9 & 2739.79 & 20 \\
\hline Category 1 & 21 & 7 & 2 & 28 & 55 & 0 & 89.87 & 35 \\
\hline Category 2 & 31 & 4 & 4 & 39 & 55 & 6 & 124.24 & 38 \\
\hline
\end{tabular}

The participation ratio of growers in Shaanxi in productive services of vegetable knowledge training and post-production refrigeration is not high. (1) For vegetable growers, capital accumulation is significant for increasing the production and income of vegetables. Hence, the local governments in Shaanxi, Hebei, and Shandong are actively helping vegetable growers to improve their professional knowledge of vegetable planting and management, but the proportion of growers in Shaanxi receiving training is the lowest of the three areas. The authors found out from the field survey that growers in Shaanxi do not know much about the training of the government or agricultural material shops, and even their planting patterns are still at the stage of relying on their own traditional experiences. Vegetable production needs exemplary management in the culture of seedlings, fertilizer use, and pesticide management. The insufficient knowledge reserve of growers has become a significant factor restraining industrial upgrades. In Hebei, the local government has actively carried out relevant training by taking advantage of its proximity to many scientific research institutes in Beijing. Not only that, but agricultural material shops also provide supportive services for agricultural materials. (2) The participation ratio of growers in post-production refrigeration is the lowest in Shaanxi, closely related to its low per mu yield and income level. Through a survey, the authors found that the concern of growers in Shaanxi about participating in post-production refrigeration is that the refrigeration cost is too high, which will affect their sales revenue. Overall, growers in Shaanxi are affected by small scale, low yield, and low unit selling price. Therefore, they need to contribute a certain amount for refrigeration, and their sales are different. This has led to the inability of growers to co-finance the establishment of cold storage and the low enthusiasm of growers to participate in refrigeration, resulting in a high amount of fresh vegetables being abandoned. By contrast, growers in Hebei have a higher per mu yield and higher unit selling price, and they are more enthusiastic about participating in post-production refrigeration to reduce the vegetable loss caused by rotting.

\section{Conclusions}

The local development experience-sharing opportunity has had a significant impact on fostering an accessible, critical, and integrated examination of local and regional development theory, institutions, and policy. Over the past three decades, China's economy has been going through massive structural changes, including vegetable productiveness. The 
study provides a theoretically informed critical analysis of contemporary local development in an international and multi-disciplinary context, grounded in concrete empirical analysis from experiences in the local context of China. It concludes by identifying what might constitute holistic, inclusive, progressive, and sustainable local development opportunities. Growers learn from the experience of other regions according to their categories and characteristics, promoting the industrial upgrading of vegetable growers more pertinently. This study intended to provide a comparative analysis regarding production structures among the Shaanxi, Hebei and Shandong provinces and portrayed a theoretical framework fostering the development opportunities for the vegetable industries of Shaanxi. We found significant development opportunities for Shaanxi's vegetable industries, as the province possessed geographically different production structures from Shandong and similar structures to Hebei. Compared with Hebei and Shandong, which both have advantages in the vegetable industry, the vegetable industry in Shaanxi is still in the catching-up stage. The two categories of tomato growers in Hebei have similar planting characteristics to those in Shaanxi, but the production characteristics of growers in Shaanxi are different from those of growers in Shandong. Therefore, tomato growers in Hebei are the desired learning object for growers in Shaanxi.

As comprehensive information on social consumption is not available for growers, the government should obtain such information and enhance the quality of upgrading information through various methods and provide them to growers to promote industrial upgrading. The local government of Shaanxi should promote industrial development by extending facilities such as formulating information-sharing platforms, introducing innovative technologies, and improving storage facilities. The incorporative structure of "agricultural enterprises, agricultural stores, typical growers" and the technical training and productive service provision of Hebei is a potential for Shaanxi. Specifically, the local government can select a batch of pilot villages and towns and agricultural stores, growers of different planting patterns, and related enterprises to pertinently investigate the development experience of suburban agriculture in Hebei or invite technical experts from Hebei to guide the development of the local vegetable industry.

The bottleneck of insufficient labor supply structure for growers in Shaanxi is alleviated by developing mutual aid for agricultural machinery. The labor input per mu of growers of the same category in Shaanxi is lower than that of the related growers in Hebei, which results in a higher cost of machinery input for growers in Shaanxi. Large-scale growers in Shaanxi have lower labor input and are more capable of purchasing machinery (the input cost of machinery is higher). The government can strengthen agricultural machinery cooperation among growers, especially between small and large-scale growers. Seemingly, higher subsidies for machinery procurement should be imposed. These are effective measures to alleviate the insufficient labor supply structure during industrial upgrading. However, this study suggests that the government should first determine the characteristics of growers, select the areas of growers with a high unit selling price of vegetables and high capital accumulation, and finally invest in cold storage. In addition, the refrigeration price should be regulated so that more growers can use cold storage to reduce the waste rate of vegetables.

Interestingly, this study only focused on tomato farmers, which could provide insight the whole industry. However, future research is needed to focus on a broader range of subjects, such as other vegetable or fruit industries. In addition, the study area is only three provinces in China (although the research area is representative), which could not reflect the whole country's situation. Future research needs to capture a wider area with diverse agricultural industrial areas as potential learning objects. If structural changes in agriculture such as farm scale, farmer's vegetable production size and capabilities, interpersonal barriers of competitiveness, product and input market risks could have been included within the framework more insights could have been gained into China's agricultural industry. Future research should include those control factors for outlining more robust outcomes. Moreover, this study does not focus on the respondent's cultivation methods, such as whether organic or ecological farming affects the price of tomatoes or not, which 
may produce some incomplete outcomes. Future research should test the model within the different aspects of farming methods and run a comparative analysis among them. This study utilized the price of tomatoes as the indicator of quality, which could provide biased results as the price of this vegetable is largely influenced by several factors such as production methods, regional values, and impacts of seasonality. Moreover, within a dynamic market like China, where cultural values and products from specific regions gain much preference, other factors need to be taken into account. Likewise, the harvesting time and cultural influences should also be considered to gain more accurate outcomes. As the research material of the study was restricted to some specific regions, it could have been more robust if the factors like family kinship, whether farmers received training or not, distance from the nearest market, conditions of intermediaries, financial infrastructure, and other socioeconomic factors were included within the external factors. Hence, it is obvious that, while capital can do nothing without labor, labor could never rise above a state of barbarism without capital. Therefore, future research should highlight the interrelationships between these two factors. The level of production costs, production intensity, and technological interventions should also be included within the core framework.

Author Contributions: Conceptualization: H.W. and A.S.; data curation: H.W., M.S.H. and A.S.; formal analysis: H.W. and A.S.; investigation: H.W. and A.S.; resources: A.R., M.S.H. and L.Q.; software: H.W., A.R. and A.S.; validation: H.W., W.H.M. and A.S.; writing-original draft: H.W., W.H.M. and A.S.; writing-reviewing and editing: A.S., H.W., W.H.M. and L.Q.; funding acquisition: A.R., M.S.H., L.Q. and W.H.M.; resources and supervision: L.Q. All authors have read and agreed to the published version of the manuscript.

Funding: This study is supported by the National Natural Science Foundation of China (Grant Number-7197030867).

Institutional Review Board Statement: As this study does not involve any personal data and the respondents were well aware that they could opt-out at anytime during the data collection phase, any written institutional review board statement is not required.

Informed Consent Statement: As the study does not involve any personal data and the respondents were well aware that they could opt-out at anytime during the data collection phase, any written Informed Consent Statement is not required.

Data Availability Statement: The associated dataset of the study is available upon request to the corresponding author.

Acknowledgments: The authors are grateful to Asfikur Rahman, faculty member, School of Social Science, Khulna University, and Saleh Mohammad Shariar, College of Economics and Management, Northwest A\&F University, for critically reviewing the study and valuable inputs for improving the quality of the study. We extend our gratitude to Rob Gilles, Queens Management School, Queens University Belfast, for the help with the improvement of the study's presentation.

Conflicts of Interest: The authors declare no conflict of interest.

\section{References}

1. Park, S.H.; Li, S.; Tse, D.K. Market Liberalization and Firm Performance during China's Economic Transition. J. Int. Bus. Stud. 2006, 37, 127-147. [CrossRef]

2. Chambers, W.; King, R.P. Changing Agricultural Markets: Industrialization and Vertical Coordination in the Dry Edible Bean Industry. Appl. Econ. Perspect. Policy 2002, 24, 495-511. [CrossRef]

3. Pike, A.; Rodríguez-Pose, A.; Tomaney, J. Local and Regional Development, 2nd ed.; Routledge: London, UK, 2016; ISBN 978-1-31576767-3.

4. Jannat, A.; Islam, M.M.; Alamgir, M.S.; Al Rafi, D.A.; Ahmed, J.U. Impact Assessment of Agricultural Modernization on Sustainable Livelihood among Tribal and Non-Tribal Farmers in Bangladesh. GeoJournal 2021, 86, 399-415. [CrossRef]

5. Xie, J.; Yu, J.; Chen, B.; Feng, Z.; Lyu, J.; Hu, L.; Gan, Y.; Siddique, K.H.M. Gobi Agriculture: An Innovative Farming System That Increases Energy and Water Use Efficiencies. A Review. Agron. Sustain. Dev. 2018, 38, 62. [CrossRef]

6. He, Y.; Deng, W.; Zhang, L. Evaluation of Agricultural Modernization Based on Maximizing Deviation and GMDH. In Proceedings of the Seventh International Conference on Management Science and Engineering Management, Philadelphia, PA, USA, 7-9 November 2013; Xu, J., Fry, J.A., Lev, B., Hajiyev, A., Eds.; Springer: Berlin/Heidelberg, Germany, 2014; pp. 1195-1205. 
7. Zheng, X. Drawing upon the Experience and Lessons of the Netherlands and Japan to Accelerate Agricultural Modernization. In China's 40 Years of Economic Reform and Development: How the Miracle Was Created; Zheng, X., Ed.; Springer: Singapore, 2018; pp. 315-319, ISBN 9789811327278.

8. Hogeland, J.A. Managing Uncertainty and Expectations: The Strategic Response of U.S. Agricultural Cooperatives to Agricultural Industrialization. J. Co-Oper. Organ. Manag. 2015, 3, 60-71. [CrossRef]

9. MacMillan, T.; Benton, T.G. Agriculture: Engage Farmers in Research. Nature 2014, 509, 25-27. [CrossRef]

10. Zhu, H.A.N. The Enlightenment of the Agricultural Industrialization and Distribution System of Agricultural Products in Japan. China Bus. Mark. 2011, 10, 23-57.

11. Hisano, S.; Akitsu, M.; McGreevy, S.R. Revitalising Rurality under the Neoliberal Transformation of Agriculture: Experiences of Re-Agrarianisation in Japan. J. Rural Stud. 2018, 61, 290-301. [CrossRef]

12. Zheng, X. Facilitating Coordinated Agricultural Modernization, Industrialization and Urbanization. In China's 40 Years of Economic Reform and Development: How the Miracle Was Created; Zheng, X., Ed.; Springer: Singapore, 2018; pp. 279-284, ISBN 9789811327278.

13. Chandio, A.A.; Jiang, Y.; Wei, F.; Guangshun, X. Effects of Agricultural Credit on Wheat Productivity of Small Farms in Sindh, Pakistan: Are Short-Term Loans Better? Agric. Financ. Rev. 2018, 78, 592-610. [CrossRef]

14. Hui, J.; Zhaoyang, L.I.U. The Spatial Distribution and Influencing Factors of the Leading Enterprises in China's Agricultural Industrialization. J. Jishou Univ. Soc. Sci. Ed. 2020, 41, 94. [CrossRef]

15. Huang, J.; Otsuka, K.; Rozelle, S. Agriculture in China's Development: Past Disappointments, Recent Successes, and Future Challenges. In China's Great Economic Transformation; Brandt, L., Rawski, T.G., Eds.; Cambridge University Press: Cambridge, UK, 2008; pp. 467-505, ISBN 978-0-521-88557-7.

16. Zheng, X. China Has Great Potential to Join the Ranks of High-Income Countries. In China's 40 Years of Economic Reform and Development: How the Miracle Was Created; Zheng, X., Ed.; Springer: Singapore, 2018; pp, 173-180, ISBN 9789811327278.

17. Carrillo, M.J. Migrant Flows: Hydraulic Infrastructure, Agricultural Industrialization, and Environmental Change in Western Mexico, 1940-1964. Environ. Hist. 2021, 26, 231-254. [CrossRef]

18. Li, X.; Huang, D. Research on Value Integration Mode of Agricultural E-Commerce Industry Chain Based on Internet of Things and Blockchain Technology. Available online: https://www.hindawi.com/journals/wcmc/2020/8889148/ (accessed on 19 February 2021).

19. Lin, J.Y.; Wang, Y. China's Integration with the World: Development as a Process of Learning and Industrial Upgrading; Policy Research Working Papers; The World Bank: Washington, DC, USA, 2009.

20. Zhao, X. Research on the Development of Rural Industrial Integration. In Proceedings of the 2019 4th International Conference on Financial Innovation and Economic Development (ICFIED 2019), Sanya, China, 18-20 January 2019; Atlantis Press: Dordrecht, The Netherlands; pp. 270-273.

21. Benešová, I.; Novotná, Z.; Šánová, P.; Laputková, A. Economic Comparison of Agricultural Sector of Eurasian Countries-Is There Any Potential for Development Through Economic Cooperation? AOL 2016, 2, 19-31. [CrossRef]

22. Rusliyadi, M.; Libin, W. Agriculture Development Programs for Poverty Reduction Evidences from Indonesia and ChinaComparative Study Case. Asian J. Agric. Rural Dev. 2018, 8, 104-118. [CrossRef]

23. Bosena, T.; Bekabil, F.; Gebremedhin, B.; Hoekstra, D. Structure-Conduct-Performance of Cotton Market: The Case of Metema District, Ethiopia. J. Agric. Biotechnol. Ecol. 2011, 4, 1-12.

24. Ferguson, P.R.; Ferguson, G.J. The Structure-Conduct-Performance Paradigm. In Industrial Economics: Issues and Perspectives; Ferguson, P.R., Ferguson, G.J., Eds.; Macmillan Education UK: London, UK, 1998; pp. 13-37, ISBN 978-1-349-23306-9.

25. Kumar, B.G.; Datta, K.K.; Joshi, P.K.; Katiha, P.K.; Suresh, R.; Ravisankar, T.; Ravindranath, K.; Menon, M. Domestic Fish Marketing in India-Changing Structure, Conduct, Performance and Policies. Agric. Econ. Res. Rev. 2008, 21, 345-354. [CrossRef]

26. Hendrickson, J.; Sassenrath, G.F.; Archer, D.; Hanson, J.; Halloran, J. Interactions in Integrated US Agricultural Systems: The Past, Present and Future. Renew. Agric. Food Syst. 2008, 23, 314-324. [CrossRef]

27. Kremen, C.; Iles, A.; Bacon, C. Diversified Farming Systems: An Agroecological, Systems-Based Alternative to Modern Industrial Agriculture. Ecol. Soc. 2012, 17, 44. [CrossRef]

28. Trivelli, L.; Apicella, A.; Chiarello, F.; Rana, R.; Fantoni, G.; Tarabella, A. From Precision Agriculture to Industry 4.0: Unveiling Technological Connections in the Agrifood Sector. Br. Food J. 2019, 121, 1730-1743. [CrossRef]

29. Khandker, S.R.; Koolwal, G.B. How Infrastructure and Financial Institutions Affect Rural Income and Poverty: Evidence from Bangladesh. J. Dev. Stud. 2010, 46, 1109-1137. [CrossRef] [PubMed]

30. Ugwu, D.S.; Kanu, I.O. Effects of Agricultural Reforms on the Agricultural Sector in Nigeria. JASD 2012, 4, 51-59. [CrossRef]

31. Li, T.; Yu, W.; Baležentis, T.; Zhu, J.; Ji, Y. Rural Demographic Change, Rising Wages and the Restructuring of Chinese Agriculture. China Agric. Econ. Rev. 2017, 9, 478-503. [CrossRef]

32. Park, A.; Jin, H.; Rozelle, S.; Huang, J. Market Emergence and Transition: Arbitrage, Transaction Costs, and Autarky in China's Grain Markets. Am. J. Agric. Econ. 2002, 84, 67-82. [CrossRef]

33. Gale, F. China's Pork Imports Rise Along with Production Costs; United States Department of Agriculture: Washington, DC, USA, 2017.

34. Rocadembosch, J.; Amador, J.; Bernaus, J.; Font, J.; Fraile, L.J. Production Parameters and Pig Production Cost: Temporal Evolution 2010-2014. Porc. Health Manag. 2016, 2, 11. [CrossRef] [PubMed] 
35. Yan-hua, S.; Fa-ming, Z.; Xiang-hui, L. Explore and Analyze the Risk Management of Pig Industry Value Chain in China-From the Angle of Farmer. In Proceedings of the 2010 International Conference on Electrical and Control Engineering, Wuhan, China, 25-27 June 2010; pp. 952-955.

36. Thakur, M.; Hurburgh, C.R. Framework for Implementing Traceability System in the Bulk Grain Supply Chain. J. Food Eng. 2009, 95, 617-626. [CrossRef]

37. Xu, S.; Wu, J.; Song, W.; Li, Z.; Li, Z.; Kong, F. Spatial-Temporal Changes in Grain Production, Consumption and Driving Mechanism in China. J. Integr. Agric. 2013, 12, 374-385. [CrossRef]

38. Schmit, T.M.; Severson, R.M.; Strzok, J.; Barros, J. Improving Economic Contribution Analyses of Local Agricultural Systems: Lessons from a Study of the New York Apple Industry. J. Agric. Food Syst. Community Dev. 2019, 8, 37-51. [CrossRef]

39. Mgendi, G.; Shiping, M.; Xiang, C. A Review of Agricultural Technology Transfer in Africa: Lessons from Japan and China Case Projects in Tanzania and Kenya. Sustainability 2019, 11, 6598. [CrossRef]

40. Evonne, Y.; Akira, N.; Kazuhiko, T. Comparative Study on Conservation of Agricultural Heritage Systems in China, Japan and Korea. JORE 2016, 7, 170-179. [CrossRef]

41. Zhang, L.; Tang, X.; Wang, J. Comparative Analysis on Levels and Structure of Agricultural Support Policy among China, America, EU, Japan and Korea. Sci. Technol. Manag. Res. 2016, 2016, 18.

42. De Figueiredo Junior, H.S.; Meuwissen, M.P.M.; Filho, J.d.A.; Oude Lansink, A.G.J.M. Evaluating Strategies for Honey Value Chains in Brazil Using a Value Chain Structure-Conduct-Performance (SCP) Framework. Int. Food Agribus. Manag. Rev. 2016, 19, 225-250.

43. Mu'azu, A.U.; Mohamed, Z.; Shamsudin, M.N.; Latif, I.A. Structure-Conduct-Performance of the Malaysian Poultry Industry. Aust. J. Basic Appl. Sci. 2013, 7, 170-177.

44. Relawati, R.; Mulyo, J.H.; Masyhuri, M.; Waluyati, L.R. The Structure-Conduct-Performance of Indonesian Apple Fruit Market. In Proceedings of the International Conference on Food, Agriculture and Natural Resources (FANRes 2018), Yogyakarta, Indonesia, 12-14 September 2018; Atlantis Press: Dordrecht, The Netherlands, 2018; pp. 238-243.

45. Huo, D.; Chen, Y.; Hung, K.; Song, Z.; Guan, J.; Ji, A. Diamond Model and the Export Competitiveness of the Agriculture Industry from Emerging Markets: An Exploratory Vision Based on a Spatial Effect Study Using a Genetic Algorithm. Econ. Res. -Ekon. Istraživanja 2020, 33, 2427-2443. [CrossRef]

46. Zhao, L. Determinants of Food Industry Competitiveness in China from the Perspectives of Porter's Diamond Model. In Proceedings of the 3rd International Conference on Judicial, Administrative and Humanitarian Problems of State Structures and Economic Subjects (JAHP 2018), Domodedovo, Russia, 1-4 April 2018; Atlantis Press: Dordrecht, The Netherlands, 2018; pp. 281-286.

47. Arifin, B. On the Competitiveness and Sustainability of the Indonesian Agricultural Export Commodities. Compet. Sustain. Indones. Agric. Export Commod. 2013, 1, 81-100.

48. Moreda, G.P.; Ruiz-Altisent, M. Quality of Agricultural Products in Relation to Physical Conditions. In Encyclopedia of Agrophysics, Gliński, J., Horabik, J., Lipiec, J., Eds.; Springer: Dordrecht, The Netherlands, 2011; pp. 669-678, ISBN 978-90-481-3585-1.

49. Bamigboye, F.O.; Ademola, E.O. Internet of Things (Iot): It's Application for Sustainable Agricultural Productivity in Nigeria; University of Professional Studies: Accra, Ghana, 2016; pp. 1-4.

50. Muangprathub, J.; Boonnam, N.; Kajornkasirat, S.; Lekbangpong, N.; Wanichsombat, A.; Nillaor, P. IoT and Agriculture Data Analysis for Smart Farm. Comput. Electron. Agric. 2019, 156, 467-474. [CrossRef]

51. Rahman, S.; Hussain, A.; Taqi, M. Impact of Agricultural Credit on Agricultural Productivity in Pakistan: An Empirical Analysis. Int. J. Adv. Res. Manag. Soc. Sci. 2014, 3, 125-139.

52. Sekyi, S.; Domanban, P.B.; Honya, G.K. The Impact of Informal Credit on Rural Agricultural Productivity in the Savannah Ecological Zone of Ghana. Afr. J. Econ. Manag. Stud. 2019, 11, 301-315. [CrossRef]

53. Zeller, M.; Diagne, A.; Mataya, C. Market Access by Smallholder Farmers in Malawi: Implications for Technology Adoption, Agricultural Productivity and Crop Income. Agric. Econ. 1998, 19, 219-229. [CrossRef]

54. Zhang, F.; Sarkar, A.; Wang, H. Does Internet and Information Technology Help Farmers to Maximize Profit: A Cross-Sectional Study of Apple Farmers in Shandong, China. Land 2021, 10, 390. [CrossRef]

55. Li, L.; Wang, J.; Guo, H. The Impact of Industrial Organization Models on Farmers' Production Technical Efficiency-Based on Vegetable Farmers in Hebei and Zhejiang Province. J. Agrotech. Econ. 2019, 7, 7-23.

56. Sexton, R.J.; Lavoie, N. Chapter 15 Food Processing and Distribution: An Industrial Organization Approach. In Handbook of Agricultural Economics; Marketing, Distribution and Consumers; Elsevier: Amsterdam, The Netherlands, 2001; Volume 1, pp. 863-932.

57. Carey, R.; Krumholz, F.; Duignan, K.; McConell, K.; Browne, J.L.; Burns, C.; Lawrence, M. Integrating Agriculture and Food Policy To Achieve Sustainable Peri-Urban Fruit and Vegetable Production in Victoria, Australia. J. Agric. Food Syst. Commun. Dev. 2011, 1, 181-195. [CrossRef]

58. Friedland, W.H. The Global Fresh Fruit and Vegetable System: An Industrial Organization Analysis; Cornell University Press: Ithaca, NY, USA, 2019; pp. 173-189, ISBN 978-1-5017-3603-2.

59. Matsuyama, K. Agricultural Productivity, Comparative Advantage, and Economic Growth. J. Econ. Theory 1992, 58, 317-334. [CrossRef]

60. Wang, S.L.; Tuan, F.; Gale, F.; Somwaru, A.; Hansen, J. China's Regional Agricultural Productivity Growth in 1985-2007: A Multilateral Comparison1. Agric. Econ. 2013, 44, 241-251. [CrossRef] 
61. Zhemoyda, O.V.; Gerasymenko, N. Concentration of Agriculture and Competitive Advantages of East-European Countries. In Proceedings of the European Association of Agricultural Economists 113th Seminar, Chania, Crete, Greece, 3-6 September 2009.

62. Bagchi, M.; Rahman, S.; Shunbo, Y. Growth in Agricultural Productivity and Its Components in Bangladeshi Regions (1987-2009): An Application of Bootstrapped Data Envelopment Analysis (DEA). Economies 2019, 7, 37. [CrossRef]

63. Bank, A.D. Improving Agricultural Productivity and Rural Livelihoods: A Knowledge Sharing Experience; Asian Development Bank: Mandaluyong, Philippines, 2013; ISBN 978-92-9092-041-0.

64. Leenhardt, D.; Angevin, F.; Biarnès, A.; Colbach, N.; Mignolet, C. Describing and Locating Cropping Systems on a Regional Scale. A Review. Agron. Sustain. Dev. 2010, 30, 131-138. [CrossRef]

65. Briones, R.M. Small Farmers in High-Value Chains: Binding or Relaxing Constraints to Inclusive Growth? World Dev. 2015, 72, 43-52. [CrossRef]

66. Waldron, S.; Brown, C.; Longworth, J. A Critique of High-Value Supply Chains as a Means of Modernising Agriculture in China: The Case of the Beef Industry. Food Policy 2010, 35, 479-487. [CrossRef]

67. Gulati, A.; Minot, N.; Delgado, C.; Bora, S. Growth in High-Value Agriculture in Asia and the Emergence of Vertical Links with Farmers. In Global Supply Chains, Standards and the Poor: How the Globalization of Food Systems and Standards Affects Rural Development and Poverty; CABI: Wallingford, UK, 2007; pp. 91-108.

68. Staelens, L.; Desiere, S.; Louche, C.; D'Haese, M. Predicting Job Satisfaction and Workers' Intentions to Leave at the Bottom of the High Value Agricultural Chain: Evidence from the Ethiopian Cut Flower Industry. Int. J. Hum. Resour. Manag. 2018, 29, 1609-1635. [CrossRef]

69. Lin, J.Y. New Structural Economics: A Framework for Rethinking Development and Policy; The World Bank: Washington, DC, USA, 2012; ISBN 0-8213-8955-6.

70. Lin, J.Y. New Structural Economics: A Framework for Rethinking Development. World Bank Res. Obs. 2011, $26,193-221$. [CrossRef]

71. Stojčić, N. Prikaz Knjige: New Structural Economics: A Framework for Rethinking Development and Policy. Zb. Rad. Ekon. Fak. Rijeci Časopis Ekon. Teor. Praksu 2013, 31, 309-311.

72. Vuckovic, V. New Structural Economics: A Framework for Rethinking Development and Policy. Croat. Econ. Surv. 2014, 16, 161.

73. Lin, J.Y.; Rosenblatt, D. Shifting Patterns of Economic Growth and Rethinking Development. J. Econ. Policy Reform 2012, 15, 171-194. [CrossRef]

74. Obeng-Odoom, F. Rethinking Development Economics: Problems and Prospects of Georgist Political Economy. Rev. Polit. Econ. 2021, 1-18. [CrossRef]

75. Lin, J.Y.; Monga, C. Growth Identification and Facilitation: The Role of the State in the Dynamics of Structural Change; Policy Research Working Papers; The World Bank: Washington, DC, USA, 2010.

76. Xu, J. Growth Identification and Facilitation Framework: A Pragmatic Approach for Promoting Economic Structural Transformation. In Future Fragmentation Processes: Effectively Engaging with the Ascendancy of Global Value Chains; Commonwealth Secretariat: London, UK, 2017; pp. 206-211.

77. Li, K.; Lin, B. Economic Growth Model, Structural Transformation, and Green Productivity in China. Appl. Energy 2017, 187, 489-500. [CrossRef]

78. Lin, J.Y. The Quest for Prosperity; Princeton University Press: Princeton, NJ, USA, 2014; ISBN 978-1-4008-5225-3.

79. Min, Z.H.I. The Research on Development of Modern Agriculture in Shaanxi. J. Xi'an Univ. Financ. Econ. 2010, 6, 12-36.

80. Wang, S.; Wang, Z.; Zhang, Y.; Wang, J.; Guo, R. Pesticide Residues in Market Foods in Shaanxi Province of China in 2010. Food Chem. 2013, 138, 2016-2025. [CrossRef] [PubMed]

81. Feike, T.; Chen, Q.; Graeff-Hönninger, S.; Pfenning, J.; Claupein, W. Farmer-Developed Vegetable Intercropping Systems in Southern Hebei, China. Renew. Agric. Food Syst. 2010, 25, 272-280. [CrossRef]

82. Zhang, F.; Liu, F.; Ma, X.; Guo, G.; Liu, B.; Cheng, T.; Liang, T.; Tao, W.; Chen, X.; Wang, X. Greenhouse Gas Emissions from Vegetables Production in China. J. Clean. Prod. 2021, 317, 128449. [CrossRef]

83. Bacher, J.; Wenzig, K.; Vogler, M. SPSS TwoStep Cluster-A First Evaluation. SSOAR 2004, 2004-2. Available online: https: / / www.ssoar.info/ssoar/handle/document/32715 (accessed on 19 February 2021).

84. Diday, E.; Simon, J.C. Clustering Analysis. In Digital Pattern Recognition; Fu, K.S., Ed.; Communication and Cybernetics; Springer: Berlin/Heidelberg, Germany, 1976; pp. 47-94, ISBN 978-3-642-96303-2.

85. Fu, Z.; Tian, Z.; Xu, Y.; Qiao, C. A Two-Step Clustering Approach to Extract Locations from Individual GPS Trajectory Data. Isprs Int. J. Geo-Inf. 2016, 5, 166. [CrossRef]

86. Benassi, M.; Garofalo, S.; Ambrosini, F.; Sant'Angelo, R.P.; Raggini, R.; De Paoli, G.; Ravani, C.; Giovagnoli, S.; Orsoni, M.; Piraccini, G. Using Two-Step Cluster Analysis and Latent Class Cluster Analysis to Classify the Cognitive Heterogeneity of Cross-Diagnostic Psychiatric Inpatients. Front. Psychol. 2020, 11, 1085. [CrossRef]

87. Mayer, A.; Winkler, R.; Fry, L. Classification of Watersheds into Integrated Social and Biophysical Indicators with Clustering Analysis. Ecol. Indic. 2014, 45, 340-349. [CrossRef]

88. Kent, P.; Jensen, R.K.; Kongsted, A. A Comparison of Three Clustering Methods for Finding Subgroups in MRI, SMS or Clinical Data: SPSS TwoStep Cluster Analysis, Latent Gold and SNOB. BMC Med. Res. Methodol. 2014, 14, 113. [CrossRef] [PubMed]

89. Wei, Y.D. Regional Development in China: States, Globalization and Inequality; Routledge: London, UK, 2000; ISBN 978-0-203-18466-0. 